\title{
COMPARATIVE PREY CONSUMPTION OF A PREDATORY SPIDER, Pardosa pseudoannulata (BOSENBERG AND STRAND) ON THREE DIFFERENT DIETS
}

\author{
M. Mala, M. Jahan and K. S. Islam \\ Department of Entomology, Bangladesh Agricultural University \\ Mymensing-2202, Bangladesh
}

\begin{abstract}
Prey consumption efficiency of the wolf spider, Pardosa pseudoannulata (Boesenberg and Strand) preying on brown planthopper (BPH), Nilaparvata lugens (Stål), green leafhopper (GLH), Nephotettix virescens (Distant) and drosophila, Drosophila melanogaster was investigated in the laboratory of the Department of Entomology, Bangladesh Agricultural University, Mymensingh during the period from June 2008 to April 2009. Depending on the instars and maturity, the spiders were grouped into four different age classes, namely Class I ( $3^{\text {rd }}$ and $4^{\text {th }}$ instars), Class II ( $5^{\text {th }}$ and $6^{\text {th }}$ instars), Class III ( $7^{\text {th }}$ and $8^{\text {th }}$ instars) and Class IV (egg bearing female). When the spiders of each class was supplied with sufficient number of BPH, GLH and Drosophila then the order of the prey consumption of Class I spider was BPH > drosophila $>$ GLH and the order of the prey consumption of Class II, Class III and Class IV were BPH > GLH > drosophila. But in two cases BPH was highly preferred over drosophila and GLH in a mixed diet.
\end{abstract}

Key words : Pardosa pseudoannulata, Brown planthopper, Green leafhopper, Drosophila, Age class

\section{INTRODUCTION}

The brown planthopper (BPH), Nilaparvata lugens (Stal) (Homoptera : Delphacidae) and green leafhopper (GLH), Nephotettix virescens (Distant) (Homoptera : Cicadellidae), two major sucking pest of rice are widely distributed in tropical, subtropical and temperate regions. $\mathrm{BPH}$ is a vascular feeder and remains at the base of the plant to suck sap from the mesophyll of all stages of the growing plant. It also block the xylem and phloem by laying egg masses in the midribs of the leaf sheath and leaf blade which this reduces the yield potentiality of rice plant. Light infestation reduce plant height, crop vigour, tiller production, grain weight and increased unfilled grain per panicle (Bae and Pathak, 1970, Khush, 1977), whereas heavy infestation turns the plants yellow which dry up rapidly, known as 'Hopper burn' (Kisimoto, 1960). Green leafhopper infestation with small populations during the early stages of plant growth reduces the number of tillers, plant height and general vigour and increasing the percentages of unfilled grains (Bae, 1966). Generally the leafhopper feed on the leaves and upper parts of the plants. The feeding 
and ovipositional marks predispose plants to fungal and bacterial infection (Agati and Calica, 1949).

Farmer has largely depended on the insecticides for control of the BPH and GLH. On the other hand use of synthetic pesticides has got many limitations and undesirable side effects; these are: (i) creation of pest resurgence (ii) destruction of beneficial organisms (iii) resurgence of treated organisms (iv) out breaks of secondary pest and (v) create soil, crop and environmental pollution etc (Luckmann and Metcalf, 1975). Lately, many efforts have been made to combine various non-chemical methods with insecticides under the framework of Integrated Pest Management (IPM). The wolf spider, Pardosa pseudoannulata (Boesenberg and Strand) (Araneae : Lycosidae) is one of the most important predators of leafhopper and planthopper of rice and they reduce the insect pest populations like as insecticide (Nyffeler and Benz, 1987; Fagan et al., 1998; Geetha and Gopalan, 1999). P. pseudoannulata is one of the most predominant spiders in paddy field in South East Asia. In Asia, however, spiders are often purposely introduced into fields. In China, farmers build straw or bamboo shelters for spiders and then move these shelters to whichever paddies are experiencing pest outbreak. This method of spider augmentation led to a 60 percent reduction in pesticide use (Riechert and Bishop, 1990; Mare et al., 1999).

Drosophila, Drosophila melanogaster (Diptera : Drosophilidae) acts as an alternative prey for $P$. pseudoannulata when the numbers of brown planthoppers, green leafhoppers and other insect pests are low in the field. In Japan, spider populations can be maintained and enhanced by the release of drosophila into fields when pest insects are not abundant (Mare et al., 1999). Drosophila is one of the good diets for P. pseudoannulata because spiderlings feeding on the drosophila lived considerably longer and grew bigger. Compared to single prey species diets, a mixed diet consisting of $\mathrm{BPH}, \mathrm{GLH}$ and drosophila may increase the survival, growth, and development of spiderlings of $P$. pseudoannulata.

Considering the importance of the spider as a potential biological control agent the study was undertaken to investigate the predation efficiency of the wolf spider $P$. pseudoannulata on BPH, GLH and drosophila diet.

\section{MATERIALS AND METHODS}

The experiments were carried out in the laboratory of the Department of Entomology, Bangladesh Agricultural University, Mymensingh during the period from June 2008 to April 2009 in controlled condition. During that period, the mean temperature and relative humidity in the laboratory were $27.0 \pm 2.5^{\circ} \mathrm{C}$ and $80 \pm 5 \%$, respectively.

BPH and GLH were reared on susceptible rice Variety TN1 (Taichung Native 1). Generally 40-45 days old potted rice plant were used for mass rearing purpose. For a continuous supply of 40-45 days old rice plants, TN1 seeds were sown in seed beds at an interval of 15 days regularly starting well ahead of commencement of the experiment. All 
recommended cultural practices including fertilizer and insecticide application were followed for optimum plant growth. Watering was made in regular basis. To obtain a regular supply of BPH and GLH of different stages in net house following the standard culture technique (Heinrichs, 1985).

Drosophila was reared in artificial medium. For artificial medium preparation, $9 \mathrm{~g}$ of corn flower were taken in a $1000 \mathrm{ml}$ of conical flask and was diluted at a rate $150 \mathrm{ml}$ of distilled water. This mixture was heated for 10 minutes at $125^{\circ} \mathrm{C}$ in an autoclave. After cooling agar powder (Agarose, Anachemia, Lab grade) was added at a rate $3 \mathrm{~g} / 160 \mathrm{ml}$ in the same conical flask. This stalk was properly shaked for good mixing and heated for 10 minutes at $125^{\circ} \mathrm{C}$ in an autoclave. After cooling at $45-50^{\circ} \mathrm{C}, 60 \mathrm{ml}$ molasses and $70 \mathrm{ml}$ of distilled water were added and boiled for $3 \mathrm{~min}$ in micro oven. At the end, a mixture of $3 \mathrm{~g}$ baking powder and $3 \mathrm{ml}$ of propionic acid was added to prevent the growth of mould on the agar layer. The medium was then poured into plastic vials $(3.5 \mathrm{~cm} \times 1.5 \mathrm{~cm}:$ height $\times$ dia) on which drosophila were released.

For mass rearing, 40 pairs of sexually matured female and male drosophila were kept in 10 plastic vials containing artificial medium. Each vial contains 4 pairs of drosophila. The vials with drosophila were kept in the incubator set at $25^{\circ} \mathrm{C}$. After 7 to 10 days, adult drosophila were collected from rearing medium by inverting a glass jar $(4.5 \mathrm{~cm} \times 2.5 \mathrm{~cm}$ : height $x$ dia) on the mouth of rearing jar because the adult drosophila had a tendency to fly upwards.

Some sexually matured wolf spider, P. pseudoannulata adults with egg sac were collected from the seedbed of the experimental rice plot of Entomology, Bangladesh Agricultural University, Mymensingh by using an aspirator. Each of the collected spiders was kept immediately in test tube individually. Since, the spiders are strongly cannibalistic in nature; they were confined individually in $15 \mathrm{~cm} \times 7 \mathrm{~cm}$ glass pot. They were supplied with $\mathrm{BPH}$ as prey. When eggs were hatched, all of the spiderlings were crowed on the back of the mother spider. All of the spiderlings became detached from the mother after 2-3 days of hatching. When newly hatched spiderlings were detached from her mother's back, they were transferred to another same sized pot. To minimize cannibalism, small pieces of rice straw were put inside the pots, thus giving chance to separate the spiderling from one another. Since wolf spiders prefer to live at comparatively low temperature and shady area, they were reared in the laboratory at room temperature $\left(27 \pm 2.5^{\circ} \mathrm{C}\right)$.

Spiders were divided into four different age classes; viz. Class I ( $3^{\text {rd }}$ and $4^{\text {th }}$ instars), Class II ( $5^{\text {th }}$ and $6^{\text {th }}$ instars), Class III ( $7^{\text {th }}$ and $8^{\text {th }}$ instars) and Class IV (egg bearing female). All different age classes of spider, Class I, Class II, Class III and Class IV were kept individually inside the lamp chimneys which were starved for 24 hours. Each of the starved spiders was supplied with adult of $15 \mathrm{BPH}, 15 \mathrm{GLH}$ and 15 drosophila as a mixed food. The numbers of prey were selected on the basis of previous literature and preliminary observation. Some slice of lemon and one piece of rice stem with wrapped wet cotton at the base was supplied to the drosophila, BPH and GLH as food in the lamp chimneys. Besides this, free water was used for survival of the spider. The spiders were 
allowed to take food for 24 hours. Data were recorded on the number of BPH, GLH and drosophila consumed by the spiders. There were five replications for each class of spider. The experiments were laid out in a completely randomized manner. The ANOVA were made and mean were separated by Tukey's pairwise comparisons test (MINITAB 32 bit).

\section{RESULTS AND DISCUSSION}

The results of the present studies on the prey preference of four age classes of spider $P$. pseudoannulata on mixed (BPH, GLH and drosophila) diet were presented in Table 1. The Class I ( $3^{\text {rd }}$ and $4^{\text {th }}$ instars) spider mostly preferred BPH as their food. The spider consumed significantly the highest number of $4.60 \pm 0.25 \mathrm{BPH}$ while it consumed a minimum number of $1.40 \pm 0.25 \mathrm{GLH}$ and them also consumed $2.80 \pm 0.20$ drosophila in 24 hours from the mixed diet (BPH, GLH and drosophila). The order of the prey preference for Class I spider was BPH $>$ drosophila $>$ GLH. They prefer drosophila than GLH. Because Drosophila was smaller than GLH and easy to consume for Class I spider. The Class II (5th and 6th instars) spider consumed the highest number of $7.60 \pm 0.25 \mathrm{BPH}$ while it consumed a minimum number of $3.6 \pm 0.25$ drosophila and they also consumed $5.2 \pm 0.37$ GLH in 24 hours. The order of the prey preference for Class II spider was BPH $>$ GLH > drosophila. The Class III (7th and 8th instars) and Class IV (egg bearing female) spider preferred BPH than the GLH and drosophila as like Class II. So, the order of the prey preference for Class III and Class IV were BPH > GLH > drosophila. These three Classes of spider consumed the highest number of $\mathrm{BPH}$ and the lowest number of drosophila. The rates of consumption of $\mathrm{BPH}$ by all four classes of spider were significantly higher than the other two preys, which were presented in Fig. 1.

Table 1. Consumption of BPH, GLH and drosophila by four age classes of wolf spider, P. pseudoannulata in choice tests

\begin{tabular}{l|c|c|c|c}
\hline \multirow{2}{*}{$\begin{array}{c}\text { Type of } \\
\text { prey }\end{array}$} & \multicolumn{4}{|c}{ Mean number $( \pm$ SE) of BPH, GLH and drosophila consumed by the predator } \\
\cline { 2 - 5 } & $\begin{array}{c}\text { Class I } \\
\left(3^{\text {rd }} \text { and } 4^{\text {th }} \text { instars }\right)\end{array}$ & $\begin{array}{c}\text { Class II } \\
\left(5^{\text {th }} \text { and } 6^{\text {th }} \text { instars }\right)\end{array}$ & $\begin{array}{c}\text { Class III } \\
\left(7^{\text {th }} \text { and } 8^{\text {th }} \text { instars }\right)\end{array}$ & $\begin{array}{c}\text { Class IV } \\
\text { (egg bearing female) }\end{array}$ \\
\hline BPH & $4.60 \pm 0.25^{\mathrm{a}}$ & $7.60 \pm 0.25^{\mathrm{a}}$ & $9.40 \pm 0.25^{\mathrm{a}}$ & $6.80 \pm 0.37^{\mathrm{a}}$ \\
GLH & $1.40 \pm 0.25^{\mathrm{c}}$ & $5.20 \pm 0.37^{\mathrm{b}}$ & $7.80 \pm 0.20^{\mathrm{b}}$ & $3.40 \pm 0.25^{\mathrm{b}}$ \\
Drosophila & $2.80 \pm 0.20^{\mathrm{b}}$ & $3.60 \pm 0.25^{\mathrm{c}}$ & $5.80 \pm 0.20^{\mathrm{c}}$ & $1.80 \pm 0.20^{\mathrm{b}}$ \\
\hline
\end{tabular}

* Data in a column followed by different letter(s) are significantly different at $0.1 \%$ level of probability (Tukey's pairwise comparisons test). ${ }^{*} 5$ replications each consisting of a single spider

* Observation period 24 hours. * Class I $=3^{\text {rd }}$ and $4^{\text {th }}$ instars, Class II $=5^{\text {th }}$ and $6^{\text {th }}$ instars, Class III $=$ $7^{\text {th }}$ and $8^{\text {th }}$ instars and Class IV $=$ Egg bearing female.

The results of the present study showed that the BPH were highly preferred over drosophila and GLH $(\mathrm{P}<0.01)$ by all four classes of spider. Samal and Misra (1975) reported that Pardosa could kill about 15 to 20 adult BPH per day. Anon (1975) reported that a single wolf spider could easily consume 7 to 45 hoppers per day. Predation rates observed in the laboratory were 3.08 and 4.28 adult $\mathrm{BPH}$ for the second and the fourth 
instar spider nymphs and 13.32 and 11.48 adult BPH for adult female and adult male spiders, respectively (Chiu, 1979). The spiders searched more efficiently for $N$. lugens than for $N$. virescens and also had shorter handling time, resulting in a higher number of prey attacked. This indicated that N. lugens was the preferred prey (Heong and Rubia, 1989). The results of the present study were in conformity with to those of the above mentioned authors.

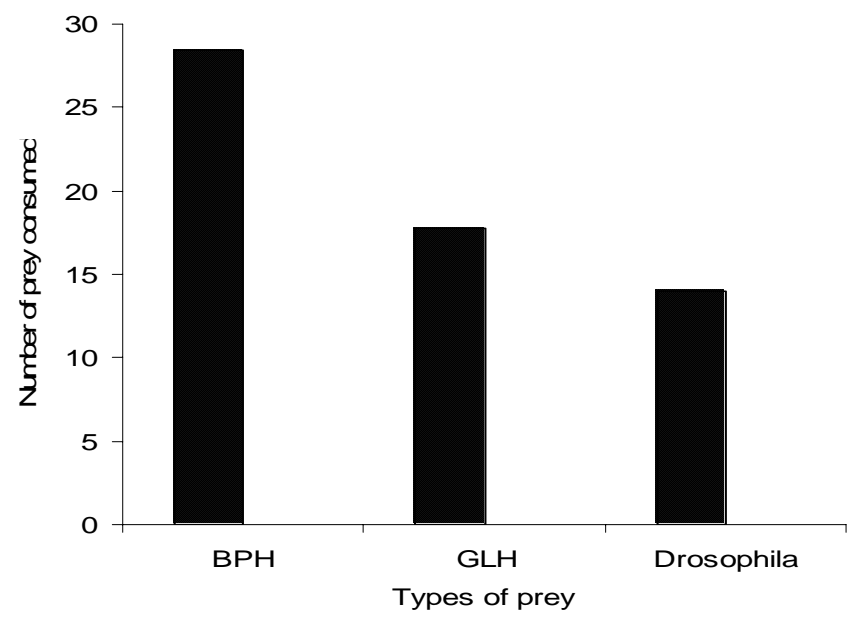

Fig. 1. Consumption of BPH, GLH and drosophila by four age classes of P. pseudoannulata

\section{CONCLUSION}

P. pseudoannulata is recognized as a significant biological control agent of insect pests in rice. It can be concluded that the predator wolf spider, $P$. pseudoannulata preferred BPH highly over GLH and drosophila. So farmer can use P. pseudoannulata for controlling BPH and GLH in their crop field. The present findings will be helpful for the researchers and the farmers to increase the population of $P$. pseudoannulata in the field as bio-control agent.

\section{REFERENCES}

Agati, J. A. and Calica, C. 1949. The leaf gall disease of rice and corn in Philippines. Philip. J. Pl. Ind., 14: 31-38.

Anonymous, 1975. Annual Review for 1974. International Rice Research Institute, Los Banos, Philippines. pp. 210-212.

Bae, S. H. 1966. Studies on some aspects of the life history and habits of the brown planthopper. Thesis, Master of Science in Entomology, University of the Philippines, College of Agriculture, Los Banos, Laguna. p. 91.

Bae, S. H. and Pathak, M. D. 1970. Life history of Nilaparvata lugens (Homoptera: Delphacidae) and susceptibility of rice varieties to its attacks. Ann. Entomol. Soc. Am., 63(1): 149-155. 
Chiu, S. C. 1979. Biological control of the brown planthopper. In: Brown Planthopper: Threat to rice Production in Asia. IRRI, Los Banos, Laguna, Philippines. p. 369.

Fagan. W. F., Hakim, A. L., Ariawan, H. and Yuliyantiningish, S. 1998. Interactions between biological control efforts and insecticide applications in tropical rice agroecosystems : The potential role of intraguild predation. Biological Control : Theory and Applications in Pest Management, 13: 121-126.

Geetha, N., and Gopalan, M. 1999. Effect of interaction predators on the mortality of nymphs of brown plant hopper, Nilaparvata lugens. Stal. J. Ent. Res., 23: 179-181.

Heinrichs, E. A., Medrano, F. G. and Rapusas, H. R. 1985. Genetic evaluation for insect resistance rice. Int. Rice Res. Inst., Los Banos, Philippines.

Heong, K. L. and Rubia, E. G. 1989. Functional response of Pardosa pseudoannulata on brown planthoppers (BPH) and green leafhoppers (GLH). Int. Rice Res. Newsl., 14(6): 29-30.

Khush, G. S. 1977. Disease and insect resistance in rice. Adv. Agron., 29: 265-341.

Kisimoto, R. 1960. Hopperburn injury formation of the brown planthopper. Japanese J. Plant Prot., 14: 377-382.

Luckmann, W.H. and Metcalf, R. L. 1975. The pest management concept. In: Metcalf, R, L. and W. H. Luckman (Eds.). Introduction of insect pest management. John wiley and sons, New York. pp. 3-35.

Mare, P., Canard, A. and Ysnel, F. 1999. Spiders (Araneae) useful for pest limitation and bionidication. Agric., Ecosyst. Environ., 74: 229-273.

Minitab, 1995. A powerful statistical software package releases 10.5 xtra for Windows Minitab Inc., USA.

Nyffeler, M. and Benz, G. 1987. Spiders in natural pest control: a review. J. Appl. Entomol., 103: 321-339.

Riechert. S. E. and Bishop, L. 1990. Prey control by an assemblage of generalist predators: spiders in garden test systems. Ecology., 71: 1441-1450.

Samal, P. and Misra, B. C. 1975. Spiders: The most effective natural enemies of the brown planthoppers in rice. Rice Entomol. Newsl., 3: 31. 